\title{
Corticosteroid therapy of experimental hydrocephalus after intraventricular-subarachnoid haemorrhage
}

\author{
H. A. WILKINSON ${ }^{1}$, RENE B. WILSON, P. P. PATEL, AND M. ESMAILI
}

From Beth Israel Hospital and Boston City Hospital, Boston, Massachusetts, U.S.A.

SYNOPSIS Symptomatic hydrocephalus after subarachnoid haemorrhage seems to result both from mechanical obstruction of arachnoid villi and basilar cisterns and from an inflammatory cellular reaction in the villi. Subarachnoid haemorrhage was induced in rabbits using whole blood injected through an implanted intraventricular needle. Control rabbits receiving intraventricular methyl prednisolone acetate but no blood, developed ventricular dilatation significantly more often than untreated controls. Eighty-three per cent of rabbits with untreated experimental subarachnoid haemorrhage developed moderate to severe hydrocephalus. Intramuscular steroid therapy significantly reduced the incidence of hydrocephalus.

In 1965 Hakim and Adams (also Adams et al., 1965) called attention to the surgically treatable nature of the syndrome of symptomatic hydrocephalus with normal cerebrospinal fluid (CSF) pressure. This type of acquired hydrocephalus, usually of the communicating type, has been documented in association with a variety of aetiologies (Messert et al., 1966; Wilkinson et al., 1966; Ojemann et al., 1969), but the majority of cases are encountered after subarachnoid haemorrhage (SAH). The resulting hydrocephalus usually causes a more or less uniform clinical syndrome characterized chiefly by the progressive evolution of akinetic dementia (Messert et al., 1966).

An excess of CSF accumulates after subarachnoid haemorrhage chiefly because of an obstruction by erythrocytes of the absorptive pathways, especially the arachnoid villi (Shabo and Maxwell, 1968b; Ellington and Margolis, 1969). CSF enters the villi from the subarachnoid space and passes through the membrane (Shabo and Maxwell, 1968a) or through a labyrinth of tubular channels within the villus (Welch and Friedman, 1960) into the blood stream. Erythrocytes contained in the CSF block the absorptive surface or channels of the villi mechanically

\footnotetext{
1 Reprint requests to Dr. Harold A. Wilkinson, Beth Israel Hospital, 330 Brookline Avenue, Boston, Mass. 02215, U.S.A.
}

(Ellington and Margolis, 1969) and by initiating a leucocytic or phagocytic inflammatory response (Shabo and Maxwell, 1968b; Alksne and Lovings, 1972).

The present study was designed to explore then possibility of preventing the evolution of significant hydrocephalus after SAH by attempting to modify the induced inflammatory response in the. arachnoid villi by adrenocorticosteroid therapy.

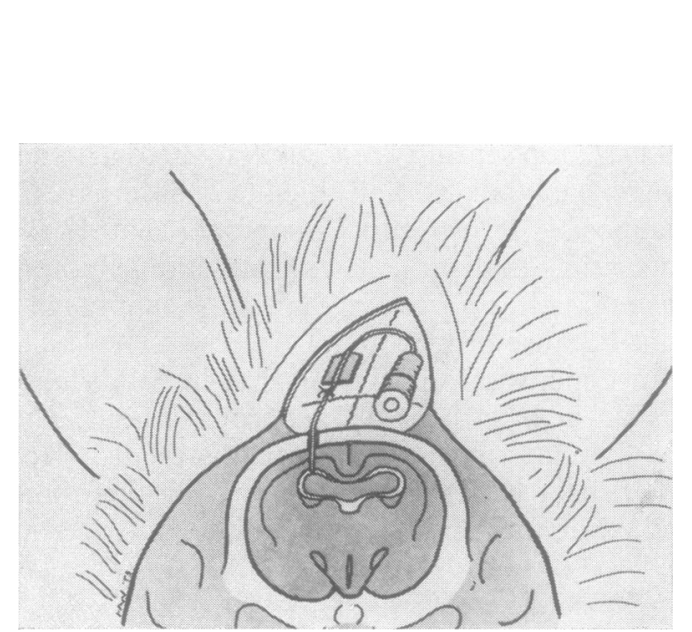

FIG. 1. Schematic drawing of coronal section through rabbit's cranium showing implanted intraventricular needle attached to repuncturable, sealed nipple. 


\section{METHODS}

One hundred and thirty-nine $5 \mathrm{~kg}$ rabbits were aseptically operated under droperidol and fentanyl (Innovar) or thiopentone anaesthesia. A no. 21 gauge needle was introduced into the lateral cerebral ventricle through a small drill hole placed $2 \mathrm{~mm}$ rostral to the coronal suture and $2 \mathrm{~mm}$ lateral to the midline, entering the ventricle at a depth of 5 or 6 $\mathrm{mm}$. The needle was fixed to the skull with stainless steel wires and methylmethacrylate plastic and was attached through a short length of tubing to a repuncturable, sealed nipple (Fig. 1). Blood injected into the ventricle through this needle passed into the subarachnoid space in all animals, as seen at necropsy and as confirmed by intraventricular injection of indigo carmine when the animals were killed.

All animals were allowed a 7 to 10 day postoperative recovery period. Four animals which displayed persistent neurological deficits during this
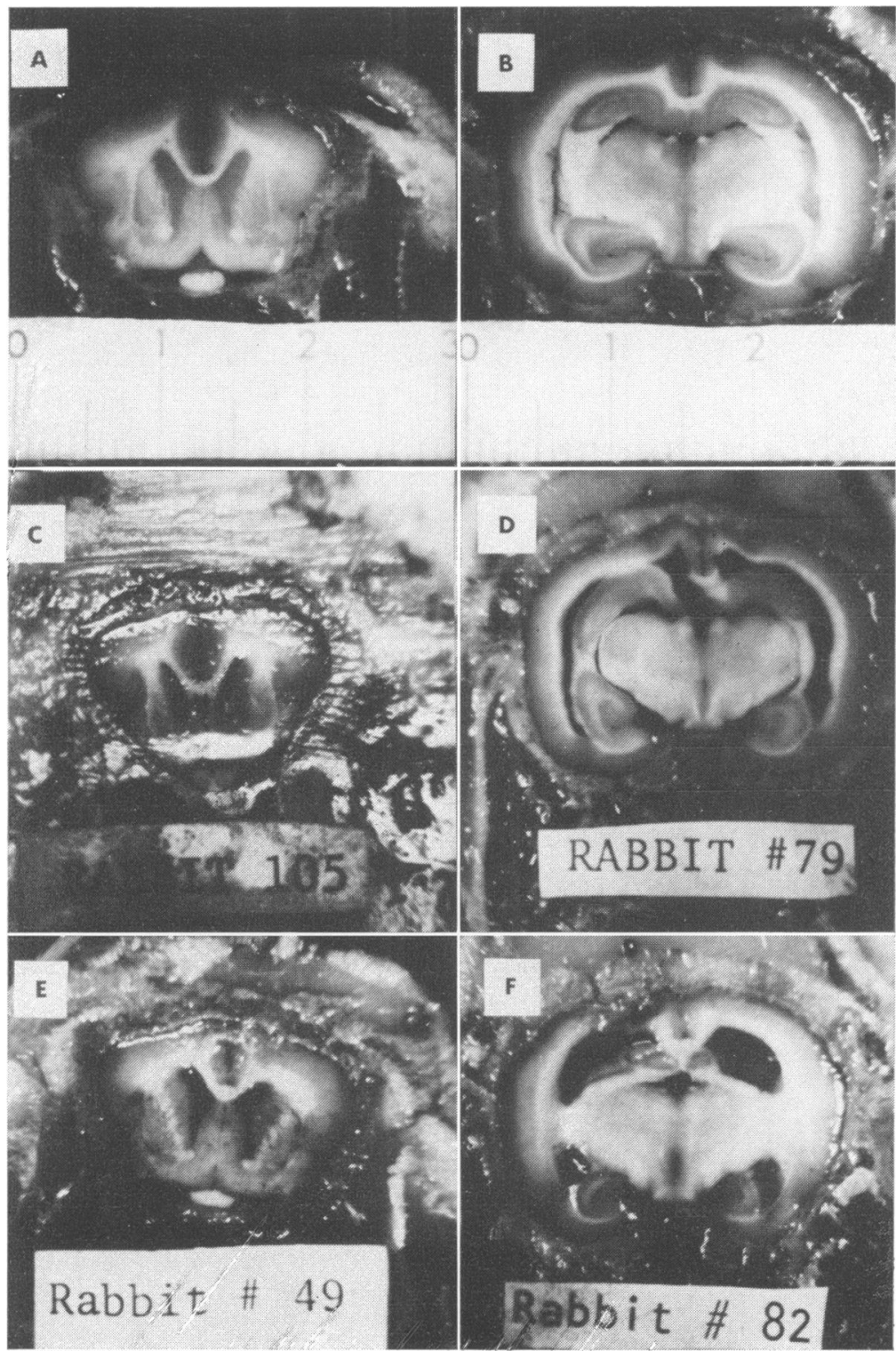

FIG. 2. Photographs of representative coronal sections through frontal horns and bodies of lateral ventricles showing no ventricular enlargement (A) and (B), mild ventricular enlargement $(\mathrm{C})$ and (D), and moderate/severe ventricular enlargement $(\mathrm{E})$ and $(\mathrm{F})$. 
period were excluded from the study. All animals were killed at the end of an additional two week period and their carcasses were frozen. The entire frozen head was sectioned with a fine-toothed saw and ventricular size was observed and photographed for later measurement. The degree of ventricular enlargement was determined from the average of a series of measurements of lateral ventricular width taken from sections through frontal horns and through the body of the ventricles; measurements of the width of the occipital horns were not included since this portion of the ventricular system frequently and variably displayed an enlargement disproportionately greater than that seen in the remainder of the ventricle. An average width of less than $0.5 \mathrm{~mm}$ was taken to represent 'normal' ventricles. A width of 0.5 to $1.2 \mathrm{~mm}$ was considered 'mild' enlargement, a width of 1.3 to $2.0 \mathrm{~mm}$ was considered 'moderate' enlargement, and a width over $2.0 \mathrm{~mm}$ was termed 'severe' enlargement (Fig. 2). Eight animals with improperly placed needles, infection, or haematomas were excluded from the study.

TABLE 1

SEVERITY OF HYDROCEPHALUS IN 'OPERATIVE' (OR UNTREATED) AND 'THERAPY' CONTROL RABBITS-ALL WITH NO INJECTIONS OF BLOOD

\begin{tabular}{|c|c|c|c|c|c|c|}
\hline \multirow{3}{*}{$\begin{array}{c}\text { Severity of } \\
\text { hydrocephalus }\end{array}$} & \multicolumn{6}{|c|}{ Therapy } \\
\hline & \multicolumn{2}{|c|}{ None } & \multicolumn{2}{|c|}{ Intraventricular } & \multicolumn{2}{|c|}{ Intramuscular } \\
\hline & (no.) & $(\%)$ & (no.) & $(\%)$ & (no.) & $(\%)$ \\
\hline $\begin{array}{l}\text { None } \\
\text { Mild } \\
\text { Moderate/Severe }\end{array}$ & $\begin{array}{l}9 \\
2 \\
0\end{array}$ & $\begin{array}{r}82 \\
18 \\
0\end{array}$ & $\begin{array}{l}5 \\
6 \\
6\end{array}$ & $\begin{array}{l}29 \\
35 \\
35\end{array}$ & $\begin{array}{l}7 \\
3 \\
1\end{array}$ & $\begin{array}{r}64 \\
27 \\
9\end{array}$ \\
\hline Totals & 11 & & 17 & & 11 & \\
\hline \multicolumn{3}{|c|}{$\begin{array}{l}\text { Statistical significance } \\
\text { of difference } \\
\text { (therapy } v \text {. no therapy) }\end{array}$} & \multicolumn{2}{|c|}{$P<0.001$} & \multicolumn{2}{|c|}{$P=0.7$} \\
\hline
\end{tabular}

Twelve rabbits died of anaesthetic complications before, during, or immediately after surgery. Their brains were examined as normal anatomical controls. Fifty-one animals were used in a preliminary study to determine the optimum dose of intraventricular blood necessary to produce hydrocephalus, while still being compatible with a reasonable two week survival. Twelve of these rabbits plus an additional 72 rabbits constituted the main study group.

Within the main study group 39 animals served as 'operative' and 'therapy' controls, receiving no intraventricular blood. Eleven of these animals were operated on but received no therapy and either no intraventricular injections or injections of $0.45 \mathrm{ml}$. Ringer lactate only. Seventeen animals received intraventricular therapy of four alternate day injections of methylprednisolone acetate (Depomedrol, Upjohn Co.) $10 \mathrm{mg}(0.25 \mathrm{ml}$.) plus $0.45 \mathrm{ml}$. Ringer lactate intraventricularly. Eleven animals received intramuscular therapy of four alternate day injections of methylprednisolone $10 \mathrm{mg}$, and intraventricular injections of $0.45 \mathrm{ml}$. Ringer lactate.

The remaining 40 rabbits in the main study group all received four alternate day injections intraventricularly of $0.25 \mathrm{ml}$. lightly heparinized whole blood obtained from the rabbits' own ear veins, plus $0.25 \mathrm{ml}$. Ringer lactate. Twelve of these animals received no therapy, 15 received intraventricular methylprednisolone therapy, and 13 received intramuscular methylprednisolone therapy on the same schedule as detailed above.

\section{RESULTS}

In the preliminary study of optimum dosage of intraventricular blood, 23 rabbits received daily intraventricular injections of blood in amounts of 0.25 to $0.50 \mathrm{ml}$. This caused severe hydrocephalus in $18(78 \%)$, but $17(74 \%)$ failed to survive the two week test period. Seven rabbits received alternate day injections of 0.40 to 0.50 $\mathrm{ml}$. blood; all of these developed moderate to severe hydrocephalus, but none survived the full test period. Twelve rabbits received alternate day injections of $0.25 \mathrm{ml}$. blood ${ }^{2}$. Ten of these developed moderate to severe hydrocephalus, and $86 \%$ survived the full test period. A dosage of $0.25 \mathrm{ml}$. blood every other day for four injections was adopted as a standard for the main study.

The results of the main study are presented in Tables 1 and 2. All of the control rabbits receiving no blood and no therapy displayed normal $(82 \%)$ or mildly enlarged ventricles $(18 \%)$ according to the measurement criteria used in the studydespite the presence of the intraventricular needle. None of these rabbits developed moderate or severe hydrocephalus. Only one control rabbit receiving intramuscular methylprednisolone therapy developed moderate ventricular enlargement, but moderate or severe enlargement developed in six $(35 \%)$ of 17 rabbits receiving intraventricular methylprednisolone

\footnotetext{
2 These rabbits served as untreated SAH controls for the main study.
} 
TABLE 2

SEVERITY OF HYDROCEPHALUS AFTER REPEATED INTRAVENTRICULAR INJECTIONS OF BLOOD-WITH AND WITHOUT THERAPY

\begin{tabular}{|c|c|c|c|c|c|c|}
\hline \multirow{3}{*}{$\begin{array}{c}\text { Severity of } \\
\text { hydrocephalus }\end{array}$} & \multicolumn{6}{|c|}{ Therapy } \\
\hline & \multicolumn{2}{|c|}{ None } & \multicolumn{2}{|c|}{ Intraventricular } & \multicolumn{2}{|c|}{ Intramuscular } \\
\hline & (no.) & $(\%)$ & (no.) & $(\%)$ & (no.) & $(\%)$ \\
\hline $\begin{array}{l}\text { None } \\
\text { Mild } \\
\text { Moderate/Severe }\end{array}$ & $\begin{array}{r}1 \\
1 \\
10\end{array}$ & $\begin{array}{r}8 \\
8 \\
83\end{array}$ & $\begin{array}{l}3 \\
4 \\
8\end{array}$ & $\begin{array}{l}20 \\
27 \\
53\end{array}$ & $\begin{array}{l}5 \\
4 \\
4\end{array}$ & $\begin{array}{l}38 \\
31 \\
31\end{array}$ \\
\hline Totals & 12 & & 15 & & 13 & \\
\hline \multicolumn{3}{|c|}{$\begin{array}{l}\text { Statistical significance } \\
\text { of difference } \\
\text { (therapy } v \text {. no therapy) }\end{array}$} & \multicolumn{2}{|c|}{$P=0.3$} & \multicolumn{2}{|c|}{$P=0.03$} \\
\hline
\end{tabular}

TABLE 3

INCIDENCE OF PREMATURE MORTALITY IN RABBITS RELATED TO SEVERITY OF HYDROCEPHALUS

\begin{tabular}{lccc}
\hline & \multicolumn{3}{c}{ Severity of hydrocephalus } \\
\cline { 2 - 4 } & None & Mild & Moderate/Severe \\
\hline $\begin{array}{c}\text { Incidence of } \\
\text { premature mortality }(\%)\end{array}$ & 11 & 40 & 38 \\
\hline
\end{tabular}

therapy, a statistically significant difference from the untreated controls. Of the animals receiving intraventricular injections of blood but no therapy, 10 out of $12(83 \%)$ developed moderate to severe hydrocephalus. With intraventricular methylprednisolone therapy this was reduced to $53 \%$, though the degree of reduction did not achieve statistical significance. With intramuscular methylprednisolone therapy this was reduced still further to $31 \%$, a reduction which is statistically significant. Although mortality was not the major end-point in this study, a definitely increased mortality was seen in those rabbits which did develop hydrocephalus (Table 3).

\section{DISCUSSION}

Symptomatic hydrocephalus with akinetic dementia is an unfortunate, but not uncommon, complication after subarachnoid haemorrhage of differing aetiologies. The hydrocephalus may evolve rapidly or insidiously and poses a severe additional burden in this patient population which is already at high risk, frequently necessitating operative, mechanical drainage of CSF through implanted shunts. Hydrocephalus has been reported to occur in man in approximately $35 \%$ of SAH due to ruptured aneurysms, with approximately $20 \%$ suffering neurological deficits (Galera et al., 1970; Krayenbuhl et al., 1972). In these rabbit experiments the incidence of hydrocephalus was $83 \%$ in the untreated group. This suggests that with repeated SAH the incidence of hydrocephalus increases.

The exact pathophysiological mechanism involved in this chronic and dementing form of hydrocephalus (often with 'low' CSF pressure) is unclear. Hakim and Adams (1965) formulated a 'hydraulic press' hypothesis emphasizing the increased force exerted by a constant pressure over a larger area-the walls of a dilated ventricular system. Geschwind (1968) rejected this hypothesis as being oversimplified, and stressed a need for consideration of the structural properties of the ventricular walls since, pathologically, dilatation of the ventricles is accompanied by a loss or compression of periventricular white matter (Yakovlev, 1947). Others have speculated on the increased absorptive surface area of dilated ventricles, allowing a return to normal CSF pressure as long as the ventricular surface area remains expanded. Presumably the accumulation of an excess of CSF initiates the pathological process, with acute distention of the cerebral ventricles. Once so disturbed, it seems then to be possible for a lower-or normal-CSF pressure to maintain this abnormal state.

Clotted blood, or red blood cells and cellular debris, in the basal cisterns or at the arachnoid villi obstructs these channels of CSF resorption and results in excessive accumulation of CSF after SAH, leading to the development of hydrocephalus. It is frequently observed clinically that blood in the CSF elicits a polymorphonuclear inflammatory response in the CSF, meningism, and fever. A focal inflammatory response to SAH has also been documented in the arachnoid villi (Shabo and Maxwell, 1969; Alksne and Lovings, 1972). It has been suggested that this inflammatory response to the presence of blood in CSF also may be an important part of the mechanism of obstruction in the acute phase of 
post-SAH hydrocephalus. Fibrous adhesions causing permanent obstruction develop late in the subarachnoid space, with significant scar production requiring more than four weeks to develop (Schemm et al., 1968). The initiating mechanism which causes the acute ventricular dilatation after SAH seems to depend on a combination of mechanical obstruction by red blood cells and debris, plus an induced inflammatory response.

The adrenocorticosteroids are frequently employed in clinical medicine for their antiinflammatory effect. One long-acting steroid preparation, methylprednisolone acetate (Depomedrol, Upjohn Co.) has been used intrathecally to provide a high CSF concentration in non-infectious inflammatory diseases of the arachnoid membrane-adhesive arachnoiditis, nerve root fibrosis, etc. (Smith and Ross, 1959; Sehgal et al., 1962; Mack, 1964; Kulick, 1965). Since the arachnoid villi are actually extensions of the arachnoid membrane, the treatment in similar fashion of an inflammatory disease of the villi caused by blood in the CSF would seem to be a logical adjunctive measure in an attempt to prevent symptomatic hydrocephalus after SAH.

In this study, adrenocorticosteroids were shown to have a definite effect in reducing the incidence of hydrocephalus after subarachnoid haemorrhage. Direct intraventricular injection of methylprednisolone was less effective than intramuscular methylprednisolone, and, in fact, caused a significant incidence of hydrocephalus in rabbits receiving no injections of blood. The lack of significant complications in reports of human intrathecal methylprednisolone therapy suggests that this might represent a species sensitivity, though it may represent simply a mechanical interference with CSF resorption by this relatively insoluble depository adrenocorticosteroid. Kulick (1965) did report occasional postinjection CSF pleocytosis in man, and Sehgal et al. (1962) advised against intracisternal injection because of severe nausea and vomiting. By injecting the methyl prednisolone intramuscularly this hydrocephalus-inducing effect was apparently avoided and a significant $(P=0.03)$ reduction in ventricular dilatation was effected.

The effectiveness of adrenocorticosteroids in lessening the incidence of significant hydrocephalus after subarachnoid haemorrhage in this study relates presumably to their known antiinflammatory effect. Their possible effect on long-term evolution of fibrous scarring of subarachnoid pathways or arachnoid villi remains conjectural (and will form the basis for continued studies). Clinically significant post-SAH hydrocephalus in humans seems to evolve only after an initial episode of acute ventricular dilatation of limited duration, presumably due to both the mechanical and the inflammatory effects of subarachnoid blood. If this acute phase can be eliminated or modified by adrenocorticosteroids, it seems reasonable to hope that a reduction in long-term, clinically significant post-SAH hydrocephalus with akinetic dementia may also be realized.

\section{REFERENCES}

Adams, R. D., Fisher, C. M., Hakim, S., Ojemann, R. G., and Sweet, W. H. (1965). Symptomatic occult hydrocephalus with 'normal' cerebrospinal-fluid pressure. A treatable syndrome. New England Journal of Medicine, 273, 117-126.

Alksne, J. F., and Lovings, E. T. (1972). The role of the arachnoid villus in the removal of red blood cells from the subarachnoid space. An electron microscope study in the dog. Journal of Neurosurgery, 36, 192-200.

Ellington, E., and Margolis, G. (1969). Block of arachnoid villus by subarachnoid hemorrhage. Journal of Neurosurgery, 30, 651-657.

Galera, R., and Greitz, T. (1970). Hydrocephalus in the adult secondary to the rupture of intracranial arterial aneurysms. Journal of Neurosurgery, 32, 634-641.

Geschwind, N. (1968). The mechanism of normal pressure hydrocephalus. Journal of Neurological Sciences, 7, 481493.

Hakim, S., and Adams, R. D. (1965). The special clinical problem of symptomatic hydrocephalus with normal cerebrospinal fluid pressure. Journal of Neurological Sciences, 2, 307-327.

Krayenbühl, H. A., Yaşargil, M. G., Flamm, E. S., and Tew, J. M., Jr. (1972). Microsurgical treatment of intracranial saccular aneurysms. Journal of Neurosurgery, 37, 678-686.

Kulick, S. A. (1965). The clinical use of intrathecal methylprednisolone acetate following lumbar puncture. Journal of the Mount Sinai Hospital, 32, 75-78.

Mack, E. W. (1964). Intrathecal steroid administration. Rocky Mountain Medical Journal, 61, no. 8, 33-34.

Messert, B., Henke, T. K., and Langheim, W. (1966) Syndrome of akinetic mutism associated with obstructive hydrocephalus. Neurology (Minneap.), 16, 635-649.

Ojemann, R. G., Fisher, C. M., Adams, R. D., Sweet, W. H., and New, P. F. J. (1969). Further experience with the syndrome of 'normal' pressure hydrocephalus. Journal of Neurosurgery, 31, 279-294.

Schemm, C. W., Bentley, J. P., and Doerfler, M. (1968). Wound healing in the subarachnoid space. Neurology (Minneap.), 18, 862-869. 
Sehgal, A. D., Gardner, W. J., and Dohn, D. F. (1962). Pantopaque 'arachnoiditis'. Treatment with subarachnoid injections of corticosteroids. Cleveland Clinic Quarterly, 29, 177-188.

Shabo, A. L., and Maxwell, D. S. (1968a). The morphology of the arachnoid villi: a light and electron microscopic study in the monkey. Journal of Neurosurgery, 29, 451-463.

Shabo, A. L., and Maxwell, D. S. (1968b). Electron microscopic observations on the fate of particulate matter in the cerebrospinal fluid. Journal of Neurosurgery, 29, 464-474.
Smith, J. K., and Ross, L. (1959). Steroid suppression of meningeal inflammation caused by Pantopaque. Neurology (Minneap.), 9, 48-52.

Welch, K., and Friedman, V. (1960). The cerebrospinal fluid valves. Brain, 83, 454-469.

Wilkinson, H. A., LeMay, M., and Drew, J. H. (1966). Adult aqueductal stenosis. Archives of Neurology, 15, 643-648.

Yakovlev, P. I. (1947). Paraplegias of hydrocephalics. (A clinical note and interpretation.) American Journal of Mental Deficiency, 51, 561-576. 